19 SPATIAL LOCALISATION OF MAGNETIC RESONANCE SPECTRA FROM NEONATAL BRAINS. Peter L. Hope, Martin J. Blackledge, N. Kevin Ives, Bheeshma Rajagopalan, Philip Sutton, George K. Radda. University of Oxford, John Radcliffe Hospital, Dept of Paediatrics and MRC Clinical MR Facility, Oxford, England

Studies of cerebral metabolism using phosphorus magnetic resonance spectroscopy ( $3{ }_{P}$ MRS) can be refined using phase modulated rotating frame imaging (PMRFI) for spatial localisation. Six full term infants were studied at 1-9 days of age, in a 1.9 tesla magnet, using a $6.5 \mathrm{~cm}$ diameter radiofrequency receiver coil overlying the temporo-parietal skull. Conventional MRS was used to obtain metabolite ratios from a large volume of one hemisphere. Spectra were then obtained, using PMRFI, from $6.5 \mathrm{~cm}$ diameter slices of corobral tissue at increasing depths up to $3.5 \mathrm{~cm}$ into the brain with $0.6 \mathrm{~cm}$ depth resolution.

Global phosphocreatine/inorganic phosphate $(\mathrm{PCr} / \mathrm{Pi})$ ratios from 4 mildly asphyxiated infants were between 1.54 and 4.35 . Two babies with severe asphyxia had ratios of 0.55 and 0.86 . The PMRE images from these two infants showed considerable heterogeneity, the $\mathrm{PCr} / \mathrm{Pi}$ ratios from slices $2 \mathrm{~cm}$ deep to the coil being $44 \%$ and $43 \%$ of the ratios from more superficial slices. The region of maximally impaired metabolism corresponds to the subcortical white matter known to be vulnerable to ischaemia.
22 PREDICTION OF PERINATAL BRAIN DAMAGE BY CORD PLASMA VASOPRESSIN (AVP), ERYTHROPOIETIN (EP), AND HYPOXANTHINE (HX) Vineta Ruth, Kari O. Raivio, Children's Hospital, University of Helsinki, Helsinki, Finland. The classical criteria of asphyxia, Apgar score and metabolic acidosis are poor predictors of perinatal brain damage. Our aim was to assess if AVP (released after stress or asphyxia). EP (synthesized after hypoxic stimulus). stress or asphyxia), EP (syntheslzed after hypoxic stimul
and HX (an ATP degradation product) are better predictors.

We measured AVP and $H X$ in umbilical arterial (UA) and EP in venous plasma of 62 infants born after preeclampsia pregnancy (PP). 31 acutely asphyxiated (AA) infants with 5-min Apgar <7 and/or UA-pH $\leq 7.05$, and 38 control infants. Neurologic follow-up at $2 \mathrm{yr}$ included Bayley score. Severe abnormality (S) was found in $4 \mathrm{PP}$ and $5 \mathrm{AA}$ infants, mild (M) in 12 and 6 . High AVP was found only in normal AA infents (geom mean;95\% conf: $303 ; 146-633$ $\mathrm{pg} / \mathrm{m} 1) ; M$ or $S$ did not differ from controls $(24 ; 8-75)$. EP was high in PP infants regardless of outcome: normal (102;69-153). $M(100 ; 37-270)$, and $S(84 ; 19-378 \mathrm{mU} / \mathrm{ml})$. AA infants with $S$ outcome had higher EP $(67 ; 33-137)$ than $M$ or normal or controls (38; $32-46)$. HX in PP infants was similar to controls. Normal AA infants had higher HX $(24 ; 17-33 \mu \mathrm{mol} / 1)$ than controls $(12 ; 10-16)$.

We conclude that neither AVP nor HX predicts brain damage. High EP after normal pregnancy, but not after preeclampsia, carries a risk for $\mathrm{CP}$ or death. BILIRUBIN NEUROTOXICITY AND BLQOD-BRAIN BARRIER OPEN-
ING IN THE RAT STUDIED USING 31 P MAGNETIC RESONANCE SPECTROSCOPY ( $31_{P}$ MRS). N. Kevin Ives, Nicholas M. Bolas, R. Mark Gardiner. (Spon. by Peter L. llope). University of Oxford, John Radcliffe Hospital, Dept of Paediatrics and MRC Clinical MR Facility, Oxford

$31_{P}$ MRS was used to investigate disruption of brain energy status by a combination of hyperbilirubinaemia and an open bloodbrain barrier (BBB). Spectra were acquired using a surface coil over the right cerebral hemisphere of anaesthetised adult male rats. Observations were made before and after intravenous infusion of bilirubin (BR, $5.2 \mathrm{mM}, 10 \mathrm{~m} 1$ in $400 \mu \mathrm{M}$ bovine serum albumin) or a control albumin solution, and after hyperosmolar BBB opening or a control albumin solution, and after hyperosmolar bia the right external carowith l-arabinose (1.8 Molal) infused via the right external caroratio of phosphocreatine $(\mathrm{PCr})$ to $\mathrm{PCr}+$ inorganic phosphate $($ Mean \pm SD).

$\left.\begin{array}{llll}\text { Control }(n=8) & \text { Baseline } & \text { BBB closed } & \text { BBB open } \\ 0.74 \pm 0.03 & 0.76 \pm 0.04 & 0.63 \pm 0.12 \\ B R(n=9) & 0.70 \pm 0.05 & 0.68 \pm 0.06 & 0.44 \pm 0.14\end{array}\right\} \begin{aligned} & P<0.001 \\ & \text { Control vs BR } \\ & \text { (ANOVA) }\end{aligned}$

These observations provide evidence in vivo that bilirubin afrects cerebral energy metabolism in the presence of an open BBB.
23 PRODUCTION OF H O BY STIMULATED PLATELETS.

Domenico Del Principe, Adriana Menichelli, Stefano Di Giulio, Walter De Matteis, Massimo Giordani, Isabe11a Savini*, Gennaro Melino*, and Alessandro Finazzi-Agrò* Depts. of Public health and Cellular Biology, and of Experimental Medicine*, University of Rome "Tor Vergata",

Rome, Italy.

Human platelets have been shown to release $\mathrm{H}_{2} \mathrm{O}_{2}$ when challenged with particulate stimuli. Here we report that platelets stimulated by thrombin also generate $\mathrm{H}_{2} \mathrm{O}$ inside, as detected by the peroxidation of the fluorogenic $2,7-\mathrm{d} 1 \mathrm{ch}$ lorofluorescein. The increase of the fluorescence is proportional to the amount of $\mathrm{H}_{2} \mathrm{O}_{2}$ generated by platelets. Under our experimental conditions, the fluorescence of intra-platelet 2,7-dichlorofluorescein is increased by $2-5$ folds by stimulation with $1 \mathrm{U} / \mathrm{ml}$ of thrombin. Intracellular catalase reduces the extent of $\mathrm{H}_{2} \mathrm{O}$ production or its steady-state concentration. The ability of platelets to produce reduced,reactive oxygen radical spectes is noteworthy, since they have been found to play a role in pathological process, like the Kawasaki disease (De1 Principe et a1.,FEBS Lett.185:142,1985).

\section{CONCENTRATION-DEPENDENT INHIBITORY EFFECT OF BILIRUBIN (B) ON PHOSPHORYLATION OF SOME} PROTEINS. T.W.R.Hansen, S.I.Walaas. Dept. of Ped. Res., U of Oslo, and Lab. for Molec. and Celi. Neurosci., The Rockefeller U, New

York, N.Y. Protein phosphorylation appears to play a central role in regulation of cell play a central role in regulation of cell
processes. We have studied the effects of $\mathrm{B} 1-320 \mu \mathrm{M}$ on processes. We have studied the effects of $\mathrm{B} 1-320 \mu \mathrm{M}$ on kinases. The proteins in concentrations of $100 \mu \mathrm{g} / \mathrm{ml}$ were phosphorylated at $30^{\circ} \mathrm{C}$ by $10 \mathrm{nM}$ concentrations of the kinases with $5 \mu$ M ATP-32P $(148 \mathrm{GBq} / \mathrm{mM})$ as phosphate donor. The reactions were stopped after $30 \mathrm{~s}$, and phosphorylation was quantitated by scintillation counting of gel pieces after SDS-polyacrylamide gel electrophoresis. B inhibited phosphorylation of the following proteins: Synapsin I by CAMP-dependent kinase $(A P K)$ and Ca/calmodulin-dependent kinase II (CaMII); glycogen synthetase by APK and CaMII; histone I by C-kinase; histone IIA by APK, CaMII, and G-kinase (GK); DARPP-32 by APK and GK; and myosin by CaMII; but not G-substrate by GK. IC 50 concentrations of $B$ varied from $20-240 \mu \mathrm{M}$. B may be capable of interfering with a wide range of protein phosphorylation reactions involved in regulation of cell metakolism.
24 OXYGEN RADICALS PRODUCE PULMONARY HIPERTENSION IN PIGS

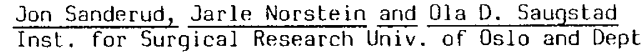
of Pediatrics, The National Hospital, Oslo, Norway. The effect of oxygen radicals on the pulmonary circulation in pigs was studied. A bolus infusion of xanthine oxidase $(X 0)$ was given with or without hypoxanthine $(H x)$ into the right atrium. Pulmonary artery pressure (PAP) and pulmonary flow (PAQ) were measured cont inuously, and the pulmonary resistance (PR) was calculated. Three groups were studied: 1) Pigs given $X 0(1 \mathrm{v} / \mathrm{kg})$. 2) Pigs given $X 0$ combined with $H x$. 3) Pigs pretreated with indomethacin $(7.5 \mathrm{mg} / \mathrm{kg})$ before infusion of xo. Results: The table shows absolute differences from basel ine

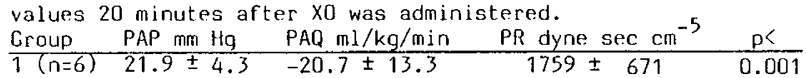
$\begin{array}{llllll}1(n=6) & 21.9 \pm 4.3 & -20.7 \pm 13.3 & 1759 \pm 671 & 0.001 \\ 2(n=5) & 29.2 \pm 4.5 & -14.0 \pm 8.3 & 1570 \pm 343 & 0.001\end{array}$ $\frac{3(n=6) \quad 9.5 \pm 8.7-5.6 \pm 7.1 \quad 571 \pm 352 \quad \text { NS }}{\text { Infusion of } X 0 \text { both with and without HX gave a significant incre- }}$ ase in PAP and PR with PAQ decreasing concomitantly. Animals pretreated with indomethacin did not show any significant differences from baselirie levels. This study demonstrates that $x 0$ potently constricts the pulmonary circulation in pigs. Since pretreatment with indomethac in only gives a blunted response, the effect may be mediated by the prostaglandin system. 